\title{
A predictive model of genital warts preventive behaviors among women in the south of Iran: application of health belief model
}

\author{
Saeideh Shahsavari ${ }^{1}$, Azin Alavi ${ }^{1}$, Parisa Razmjoue ${ }^{2}$, Shokrollah Mohseni ${ }^{3}$, Vahid Ranae ${ }^{4}$, Zahra Hosseini ${ }^{5}$ and
} Sakineh dadipoor ${ }^{6^{*}}$

\begin{abstract}
Background: Genital wart (GW) is known as an infectious disease. Besides the infection, it is associated with a higher risk of cervical neoplasia and cancer in the infected population. The present research aimed to explore the predictors of GW preventive behaviors based on the health belief model (HBM).

Methods: The present analytical and cross-sectional research was conducted in 2019 among 720 women between 15 and 49 years of age in Bandar Abbas in the south of Iran. The sample was selected in a multi-stratified clustering method. The participants responded to a reliable and valid researcher-made questionnaire which explored demographic information, knowledge-related items and the model constructs. A multivariate linear regression analysis was run to determine the predictors of adopting GW preventive behaviors. A path analysis was also run to test the direct and indirect effects of the model constructs on the dependent variable.

Results: The mean and standard deviation of participants'age was $30.43 \pm 8.697$ years. As Pearson's correlation coefficients showed, knowledge $(r=0.197, p<0.001)$, perceived susceptibility $(r=0.434, p<0.001)$, severity $(r=0.463$, $p<0.001)$ and self-efficacy $(r=0.434, p<0.001)$ were significantly correlated with the adoption of GWs preventive behaviors. Multiple linear regression analysis showed that self-efficacy $(B=-0.010, p<0.001)$, perceived susceptibility $(B=0.070, p<0.001)$ and severity $(B=0.078, p<0.001)$ were the predictors of $G W$ preventive behaviors. Path analysis showed that perceived susceptibility, severity and self-efficacy directly affected healthy behaviors while perceived benefits and barriers indirectly affected the preventive behaviors.

Conclusions: The present findings help to promote knowledge of the predictors of GW preventive behaviors. HBM can be a useful theoretical framework to evaluate the preventive behavior of the disease and help to reduce the rate of sexually-transmitted infections including GW.
\end{abstract}

Keywords: Genital warts, Women, Human papillomavirus, Health belief model

*Correspondence: mdadipoor@yahoo.com

${ }^{6}$ Social Determinants in Health Promotion Research Center, Hormozgan

Health Institute, Hormozgan University of Medical Sciences, Bandar

Abbas, Iran

Full list of author information is available at the end of the article

\section{Background}

Genital warts are known as a clinical form of human papillomavirus (HPV) infection because they are injuries in the form of single or multiple papules in the area of vulva, perineum, anus, vagina or cervix. They are typically 
associated with HPV6 and HPV11, and also with other viruses such as HPV2, 40, 42, 43 and 54 [1].

A body of related research showed that about 6.2 million new forms of GW occur annually among people between 14 and 44 years of age [2]. The prevalence and incidence rate of $\mathrm{GW}$ in Italian women was reported to be 3.8 and 3.0 per 10,000 people and $3.39 \%$ among women in Philippine [1]. GW is also prevalent among Iranian women [3-5]. Shafaghi et al. explored the prevalence of GW in 851 Iranian women, and reported 265 cases afflicted with 19 different types of HPV including GW [6].

GW is highly infectious. About $65 \%$ of individuals with an infected sex partner get afflicted with GW within 3-8 months [7]. Besides their highly infectious property, GW is associated with a high risk of cervical intraepithelial neoplasia and cancer in women with a history of GW [8]. Moreover, GW tremendously affects the quality of a patient's life [1]. It increases mental stress to a great extent. The cost imposed on the health system annually is estimated at about 200 million dollars [9]. There is yet no HPV vaccination in Iran and culturally having a sex affair is only accepted for married women. Thus, administering a test for sexually transmitted infections is a challenge for most women [10]. Evidently, trying to prevent this infection can be the best strategy in this geographical zone. A study found that preventing high-risk behaviors associated with GW can be effective in controlling this disease [8]. Moreover, preventing risky behaviors can largely depend on raising awareness and changing attitudes and beliefs [11].

A body of research in Iran reported a low level of women's and girls' knowledge of HPV and GWs [4, 12, 13]. In fact, only $8 \%$ of patients with GW showed to wear condoms [14]. However, in Hong Kong, 65\% of patients infected with HPV used condoms [15]. These facts and figures proved the absence of GW preventive behaviors in Iranian population. A study in Iran showed that raising awareness of GW can be effective in reducing the epidemic [16]. Probably, awareness-raising affects attitude, increases one's susceptibility to infection and increases the perceived risk. It, thus, has a preventive role in affliction with GW.

When GW epidemic has certain adverse effects, seemingly the first step to control the disease, as in preventing many other health threats, is to adopt preventive and protective behaviors to impede the occurrence of $\mathrm{GW}$ and prevent the cancer induced by some high-risk genotypes [17]. Health education models can be a great help in this regard. Among them is the health belief model (HBM) which explores the association between beliefs and behavior and is more involved in the prevention of diseases. The existing body of research shows that HBM is a useful framework for exploring health education topics including sex issues [18].

\section{The health belief model}

A major educational model within the health education domain is health belief model (HBM), which plays a significant role in adopting preventive behaviors. This model concerns how our perception can motivate us to behave in a certain way. Based on HBM, to adopt preventive behaviors, people should first perceive susceptibility to GW. Then, they need to perceive the severity of the disease and its adverse physical, mental, social and economic effects. People should also perceive the cues for action from their internal or external environment and prefer the perceived benefits of the preventive program to the perceived barriers (physical, economical or mental barriers to preventive behaviors). This would make them capable of showing preventive behaviors and is known as perceived self-efficacy. They will finally be capable of adopting GW preventive behaviors [19, 20] (Fig. 1).

Previous studies primarily explored the prevalence and incidence of GW among women [1,21], the major predictors of using HPV vaccination [22, 23], knowledge $[12,24]$, relationship between demographic information and GW [16] or high-risk populations with multiple sex partners or those with sexually transmitted diseases [25]. Besides, due to the dearth of regional information about GW infection [26], it needs to be explored separately in different populations. As a review of the related literature shows, the present research is pioneering in determining the predictors of GWs preventive behaviors based on HBM among women in the south of Iran. The present researchers believe that recognizing the predictors of GW preventive behaviors and providing this information to healthcare policy-makers are the major steps toward reducing the rate of the disease and its prevalence.

\section{Methods}

\section{Research design and population}

The present analytical and cross-sectional study was conducted in 2019 in Bandar Abbas in Hormozgan Province in the south of Iran. The city is of 27.19 latitude and 56.28 longitude, and is located at the height of $9 \mathrm{~m}$ above the sea level. Bandar Abbas has a population of 352,173, which makes it the largest and most populated city in Hormozgan Province. The research population comprised all women between 15 and 49 years of age selected from comprehensive healthcare centers. The inclusion criteria were being female, being between 15 and 49 years old, not being infected with sexually transmitted diseases, having no history of sexual diseases, sharing Iranian nationality and giving an informed consent to take 


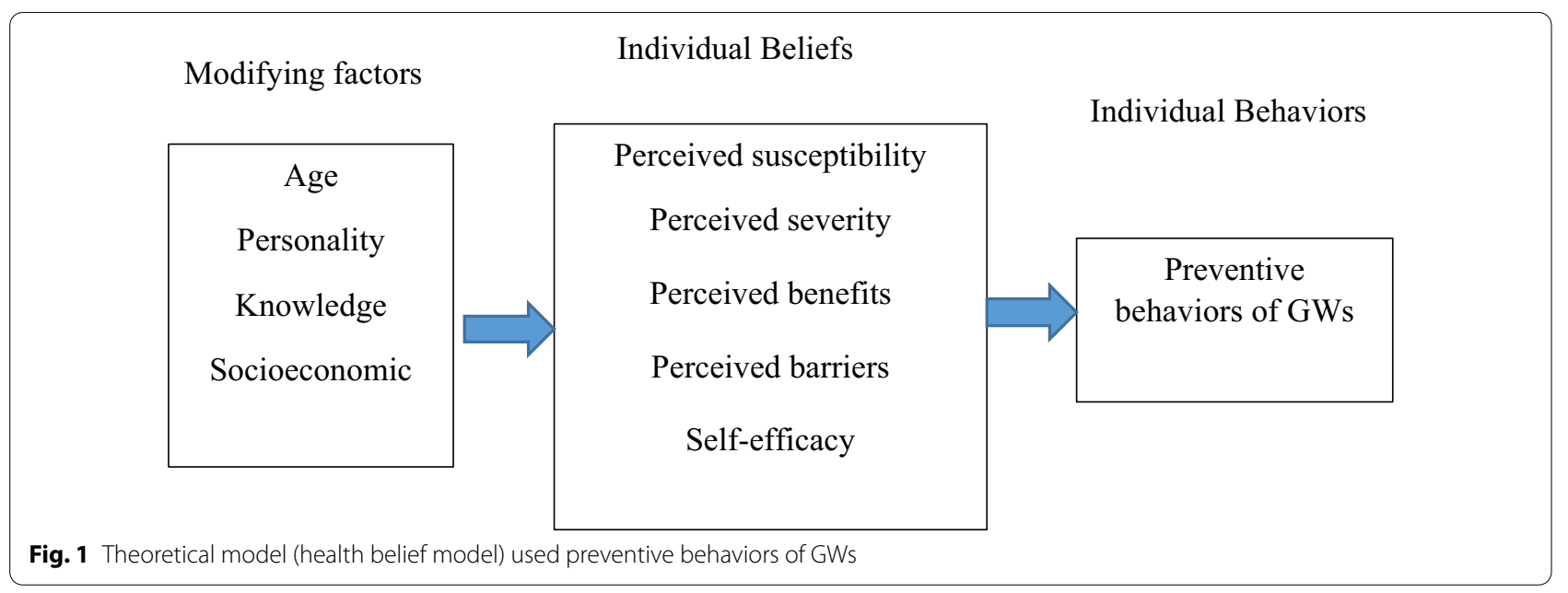

part in the research. The exclusion criterion was failure to hand in complete questionnaires.

\section{Sample size and selection}

As one purpose of this study was to determine the score of GW preventive behavior, the following formula was used to estimate the sample size: $n=\frac{z_{1-\frac{\alpha}{2}}^{2} \delta^{2}}{d^{2}}$. In the related studies, for instance, Namdar et al. [27] the score of cervical cancer preventive behavior was $1.9 \pm 1.64$. Thus, if $z_{1-\frac{\alpha}{2}}=1.96, \delta=1.64$ and $d=0.15$, the abovementioned formula gives us a sample of 460 participants. The sampling method was clustering. Thus, to estimate the final sample size, a design effect of 1.6 was considered. The final sample size was $420 \times 1.6=760$.

The participants were selected in a multi-stratified clustering method and through simple randomization. To this aim, from 20 comprehensive healthcare centers in Bandar Abbas, 15 clusters were selected and then the quota for each cluster was determined according to the population covered. To select participants from each cluster, a systematic randomization method (a list of households) was used. Then, from each cluster, a region was selected; from each region a particular street was selected, and then from each street an alley was selected to be visited. The clusters and the relevant households were visited and enlisted (including all family members living together) and then one was randomly selected which met the inclusion criteria and was visited for data collection (Fig. 2).

\section{Data collection}

The data were collected using a researcher-made questionnaire completed upon visiting the respondents' house. The questionnaire completion took about $10 \mathrm{~min}$. Literate women completed the questionnaires at home at their convenience and returned the completed questionnaires to the researcher later on. For the illiterate, the questions were read out loud by the researcher with minimal bias. If a participant who met the inclusion criteria was not present at home, the researcher revisited the house at a later time. If the researcher failed to meet the participant three times, she continued collecting data from other families so as to obtain as much information as required.

\section{Measurement procedure}

The self-administered questionnaire contained questions about: (a) demographic information, (b) knowledge of GWs (symptoms, ways of transmission, risk factors), and (c) HBM constructs.

The three parts of questionnaire will be introduced below with their content.

It is noteworthy that Part 1 and Part 2 are added (are among the moderating factors now included in the HBM model).

\section{Part 1}

This part included the participants' demographic information including their age (in years). The participants were, thus, divided into 4 age categories: $<19,20-29$, 30-39 and $>40$, marital status (married, divorced, widowed), presence of another sex partner than husband (yes/no), educational level (illiterate, below diploma, diploma, academic), occupation (not working, working outside home), socioeconomic level (lower, middle, upper) and the insurance coverage (yes/no). Socioeconomic status (SES) was based on the distribution of household crowing index (the person per room ratio). The decreasing crowdedness levels were categorized as upper, middle or lower SES (crowding index $<1$, $1-2$, and $>3$ people per room) $[28,29]$. 


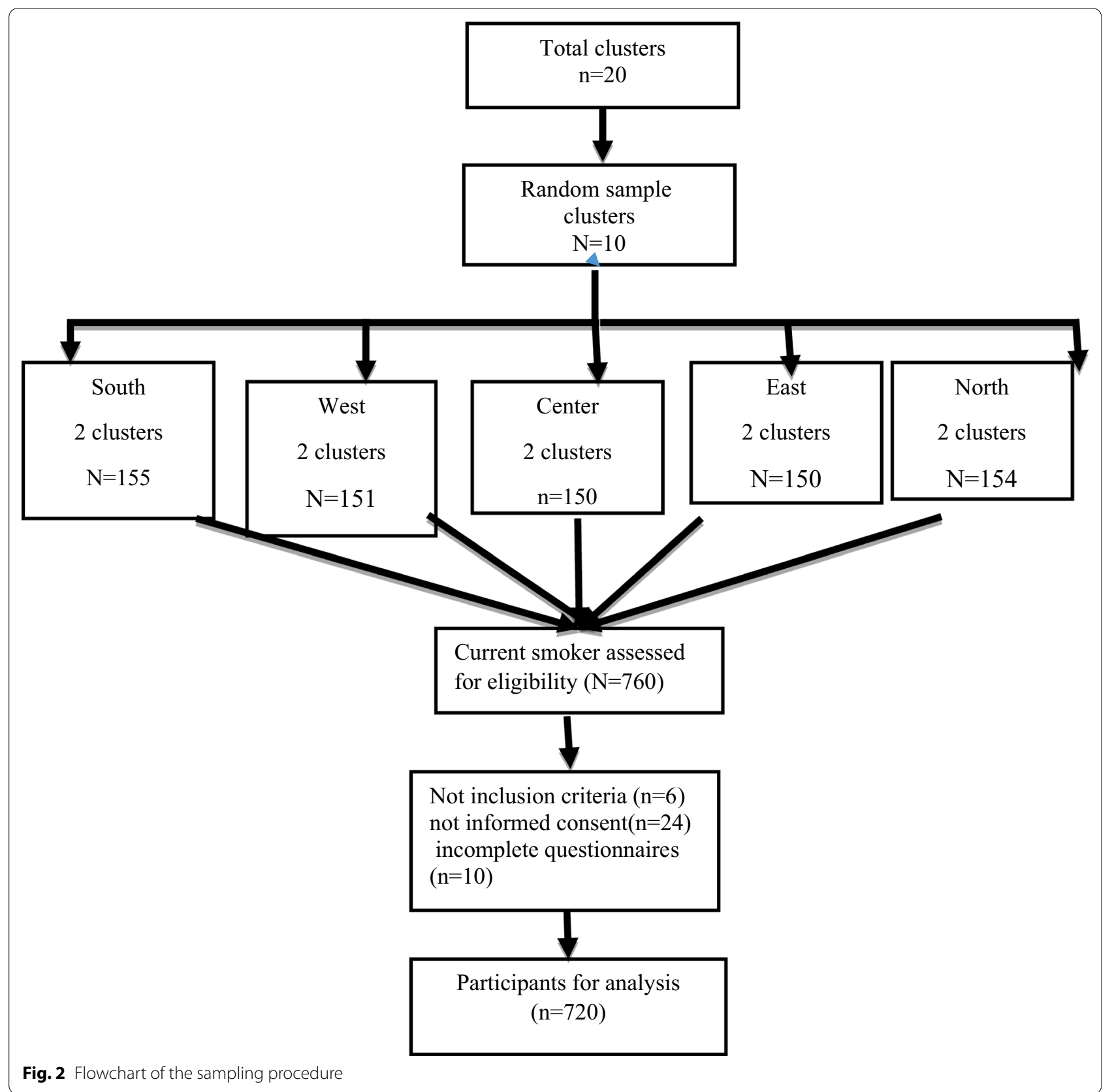

\section{Part 2}

This part explored the participants' knowledge of GW with 24 questions each with three choices (true, false, don't know). A true answer received a score of 1 while a false or don't know answer received 0 . These questions addressed aspects of knowledge including the ways of transmitting infection, symptoms and ways of preventing GWs. The reliability of the knowledge part was already substantiated in a study by Farshbaf et al. among female residents of Tabriz (a city in the northeast of Iran). The reliability coefficient was estimated at $82 \%$ [29].

\section{Part 3}

This part explored the HBM constructs and included 6 sub-scales as introduced below.

Perceived susceptibility It contained 7 items including "I have higher chances of affliction with GW in the next few years" and "Most probably I will be afflicted with GW throughout my life".

Perceived severity It contained 5 items. An instance is "I have been facing GW-related challenges and issues for years". 
Perceived benefits The timely diagnosis of GW to prevent the severe symptoms was evaluated with 7 items. Here is an instance: "An early administration of the Pap test and an early diagnosis of GW prevent extra medical costs".

Perceived barriers The adoption of GW preventive behaviors was assessed through 10 items such as: "The healthcare center is crowded and they do not have enough time to examine everyone. So, I prefer not to go".

Self-efficacy Here 6 items were used to assess an individual's capability of showing GWs preventive behaviors. Instances of items are: "I am sure I can obey sexual health rules to reduce the rate of affliction with GWs".

\section{Preventive behaviors of GW}

Healthy behavior was assessed along 4 items including: "I use condoms in every sex relationship".

All items of the sub-scales were rated on a 5-point Likert scale: (1) Strongly agree, (2) Agree, (3) Neutral, (4) Disagree, (5) Strongly disagree. Each sub-scale was scored separately and not altogether as a total score. The sub-scale scores were calculated and reported for each participant. Higher scores showed stronger feelings about a construct. All subscales had positive responses about the target behavior except for perceived barriers which was negatively associated.

\section{Data quality assurance}

To develop the questionnaire, at first, a library research was done about the topic of interest. Thus, a first draft of the questionnaire was developed based on HBM. To substantiate its content validity, the questionnaire was provided to a panel of 5 experts in health education and 5 gynecologists. Their comments were used to revise the questionnaire.

To test the reliability of the questionnaire, a test-retest method was used. To this aim, the questionnaire was provided at a 2-week's interval to 30 individuals of similar conditions to the main participants. Then, each item in the first test was compared to the retest. If the correlation coefficient between the test and retest in each scale and sub-scale was above 0.7 , the reliability was confirmed. To check the consistency of the test and retest, ICC was used, which was estimated at 0.83 and was confirmed.

\section{Ethical considerations}

To collect the required data, a formal permission was gained from the university deputy of research for visiting a sample of healthcare centers. Upon visiting the place, the researcher introduced herself completely and revealed the purpose of research for the women. Then, a written letter of consent was provided for the participants to sign. It contained all details of the research. The voluntary participation of all participants was warranted. They were asked not to reveal their identity in the questionnaires. Thus, they were assured of the confidentiality of the information they provided. This research was approved by Hormozgan University of medical sciences (\#IR.HUMS.REC.1398.267).

\section{Data analysis}

The quantitative variables were measured through descriptive statistics (standard deviation, maximum, minimum, mean, range) and the qualitative variables were described as frequencies and percentages. Pearson correlation coefficient was used to map the correlation matrix of the model constructs. Multivariate linear regression analysis was used to test a correlation between the model constructs, knowledge and behavior. A test of the association was used to explore the interrelationships among the model constructs, knowledge and behavior. Path analysis was run to test the direct and indirect effect of the model constructs on the dependent variable. To this aim, AMOS was used. The rest of analyses were conducted in SPSS21 and the significance level was set at $p<0.05$.

\section{Results}

\section{Sample characteristics}

Among the 760 questionnaires distributed, 720 were returned. Overall, 40 women were excluded from the study for not signing the informed letter of consent, missing information for a crucial item or only answering the demographic questions. The data acquired from 720 participants were finally statistically analyzed. The mean \pm SD of age, age of marriage and age of the first sex affair was $30.43 \pm 8.697,21.08 \pm 4.13$ and $20.78 \pm 4.15$ years, respectively. The majority of participants belonged to the $20-29$ year age group (40\%), were married (85.6\%), had an average SES (76.4\%), an education level below diploma (36.4\%), and were housewives $(70.3 \%)$. The other detailed demographic information is summarized in Table 1.

Table 2 summarizes the mean, median and standard deviation of knowledge, HBM constructs and preventive behaviors. As it can be seen, the scores for perceived benefits and severity were below average while other constructs were about the average score.

The correlation matrix of the HBM constructs with each other and with knowledge can be viewed in Table 3 . As the results showed, statistically significant correlations were found between all constructs except for perceived benefits and barriers with GW preventive behaviors (Table 3).

A multivariate linear regression analysis was used to test the correlation between HBM constructs and the 
Table 1 Research participants' demographic information $(n=720)$

\begin{tabular}{llcc}
\hline Variable & Categories & Frequency (n) & Percent (\%) \\
\hline Age & $<19$ & 64 & 8.9 \\
& $20-29$ & 288 & 40.0 \\
& $30-39$ & 228 & 31.7 \\
Multiple sex & $>40$ & 140 & 19.4 \\
partners & Yes & 90 & 12.5 \\
\multirow{3}{*}{ Educational level } & No & 630 & 87.5 \\
& Illterate & 62 & 8.6 \\
& Below diploma & 262 & 36.4 \\
& Diploma & 212 & 29.4 \\
Economic status & Academic & 184 & 25.6 \\
& Upper & 76 & 10.6 \\
& Middle & 550 & 76.4 \\
& Lower & 94 & 13.1 \\
Marital status & Married & 616 & 85.6 \\
& Divorced & 72 & 10.0 \\
& Widow & 32 & 4.4 \\
Working status & Working outside & 214 & 29.7 \\
& home & & 70.3 \\
& Not working & 506 & 74.2 \\
Under insurance & Yes & 534 & 25.8 \\
& No & 186 & \\
\hline
\end{tabular}

dependent variable (preventive behavior). As tabulated, perceived susceptibility, severity and self-efficacy showed statistically significant correlations; however, perceived barriers and benefits had no statistically significant correlation with GW preventive behaviors. Overall, this model managed to explain $45 \%$ of the variance in dependent variable. Among all constructs, self-efficacy showed to be the strongest predictor of the target healthy behavior $(\mathrm{B}=0.098)($ Table 4$)$.

Path analysis: The final path analysis showed that selfefficacy $(B=0.396, p<0.001)$, perceived susceptibility
$(\mathrm{B}=0.307, p<0.001)$, and perceived severity $(\mathrm{B}=0.303$, $p=0.034)$ directly affected GWs preventive behaviors. Perceived benefits and barriers had no direct effect on healthy behavior. Yet, these two variables indirectly affected the target behavior (Fig. 3).

The direct, indirect and total effects were tested too and perceived severity with a total effect of 0.455 showed to have the strongest effect. Next ranked self-efficacy, perceived susceptibility, benefits and barriers, respectively (Table 5). Overall, three variables together, self-efficacy, perceived severity and susceptibility explained $44 \%$ of the total variance in the target behavior. Two variables, perceived benefits and severity accounted for $21 \%$ of the variance in self-efficacy (Table 6). According to Table 7 , the overall goodness of fit indices attest to the model fitness.

\section{Discussion}

The present research explored the adoption of GW preventive behaviors based on HBM constructs.

To our best knowledge, so far, no similar research has been conducted using HBM or any similar model for predicting GW preventive healthy behaviors. Thus, the present research is pioneering in using HBM to predict the determinants of adopting GWs healthy behaviors.

As the results showed, knowledge, perceived susceptibility, severity and self-efficacy had statistically significant correlations with the above-mentioned healthy behavior. Among the constructs, self-efficacy was the strongest predictor of adopting GW preventive behaviors.

The present findings revealed a statistically significant correlation between knowledge and adoption of $\mathrm{GW}$ preventive behaviors. Similarly, some other research showed that a high level of knowledge could predict HPV vaccination 7.97 times as much as a low level of knowledge [30]. In their research, Sari and Syahrul maintained that $76 \%$ of women who received the HPV vaccine enjoyed a high level of knowledge. However, women who did not receive the vaccine had a moderate or low

Table 2 Mean \pm standard deviation of knowledge, HBM constructs and GWs preventive behaviors $(n=720)$

\begin{tabular}{|c|c|c|c|c|}
\hline Variable & Mean \pm SD & Median & Score range & $\begin{array}{l}\text { The percentage of score } \\
\text { obtained from the maximal } \\
\text { score }\end{array}$ \\
\hline Knowledge & $14.03 \pm 4.29$ & 14.00 & $0-22$ & 63.77 \\
\hline Perceived susceptibility & $18.18 \pm 3.68$ & 18.00 & $6-27$ & 67.33 \\
\hline Perceived severity & $17.21 \pm 3.19$ & 18.00 & $5-25$ & 68.84 \\
\hline Perceived benefits & $27.63 \pm 3.08$ & 28.00 & $18-35$ & 78.94 \\
\hline Perceived barriers & $29.55 \pm 4.51$ & 29.00 & $15-50$ & 59.1 \\
\hline Self-efficacy & $22.50 \pm 3.20$ & 22.00 & $10-30$ & 75 \\
\hline Preventive behaviors of GWs & $3.06 \pm .807$ & 3.00 & $0-4$ & 76.5 \\
\hline
\end{tabular}


Table 3 Pearson correlation coefficient of the HBM constructs and GWs preventive behaviors

\begin{tabular}{|c|c|c|c|c|c|c|c|}
\hline Variables & Knowledge $r(p)$ & $\begin{array}{l}\text { Perceived } \\
\text { susceptibility } \\
\text { r(p) }\end{array}$ & $\begin{array}{l}\text { Perceived } \\
\text { severity } r(p)\end{array}$ & $\begin{array}{l}\text { Perceived } \\
\text { benefits } r(p)\end{array}$ & $\begin{array}{l}\text { Perceived } \\
\text { barriers } r(p)\end{array}$ & Self-efficacy $r(p)$ & $\begin{array}{l}\text { Preventive } \\
\text { behaviors of } \\
\text { GWs }\end{array}$ \\
\hline Knowledge $r(p)$ & 1 & & & & & & \\
\hline $\begin{array}{l}\text { Perceived suscep- } \\
\text { tibility }\end{array}$ & $0.149(<0.001)$ & 1 & & & & & \\
\hline Perceived severity & $0.254(<0.001)$ & $0.390(<0.001)$ & 1 & & & & \\
\hline Perceived benefits & $0.307(<0.001)$ & $0.057(0.126)$ & $0.061(102)$ & 1 & & & \\
\hline Perceived barriers & $-0.326(<0.001)$ & $0.173(<0.001)$ & $0.050(0.179)$ & $-0.178(<0.001)$ & 1 & & \\
\hline Self-efficacy & $210(<0.001)$ & $0.020(0.588)$ & $0.099(0.008)$ & $0.456(<0.001)$ & $-0.143(<0.001)$ & 1 & \\
\hline $\begin{array}{l}\text { Preventive behav- } \\
\text { iors of GWs }\end{array}$ & $0.197(<0.001)$ & $0.434(<0.001)$ & $0.463(<0.001)$ & $0.027(<0.281$ & $-0.034(0.356)$ & $0.434(<0.001)$ & 1 \\
\hline
\end{tabular}

Table 4 Multivariate regression analysis of HBM constructs and GWs preventive behaviors

\begin{tabular}{|c|c|c|c|c|c|c|c|}
\hline \multirow[t]{2}{*}{ Variable } & \multicolumn{2}{|c|}{ Unstandardized coefficients } & \multirow[t]{2}{*}{$\mathrm{t}$} & \multirow[t]{2}{*}{ Sig. } & \multicolumn{2}{|c|}{$95.0 \%$ confidence interval } & \multirow[t]{2}{*}{ R square } \\
\hline & B & Std. error & & & Lower bound & Upper bound & \\
\hline (Constant) & -1.448 & 0.306 & -4.728 & 0.000 & -2.049 & -0.846 & 0.449 \\
\hline Perceived susceptibility & 0.070 & 0.007 & 10.325 & 0.000 & 0.057 & 0.083 & \\
\hline Perceived severity & 0.078 & 0.008 & 9.976 & 0.000 & 0.063 & 0.094 & \\
\hline Perceived benefits & 0.003 & 0.008 & 351 & 0.726 & -0.014 & 0.020 & \\
\hline Perceived barriers & -0.010 & 0.005 & -1.922 & 0.055 & -0.021 & 0.000 & \\
\hline Self-efficacy & 0.098 & 0.008 & 12.387 & 0.000 & 0.083 & 0.114 & \\
\hline
\end{tabular}

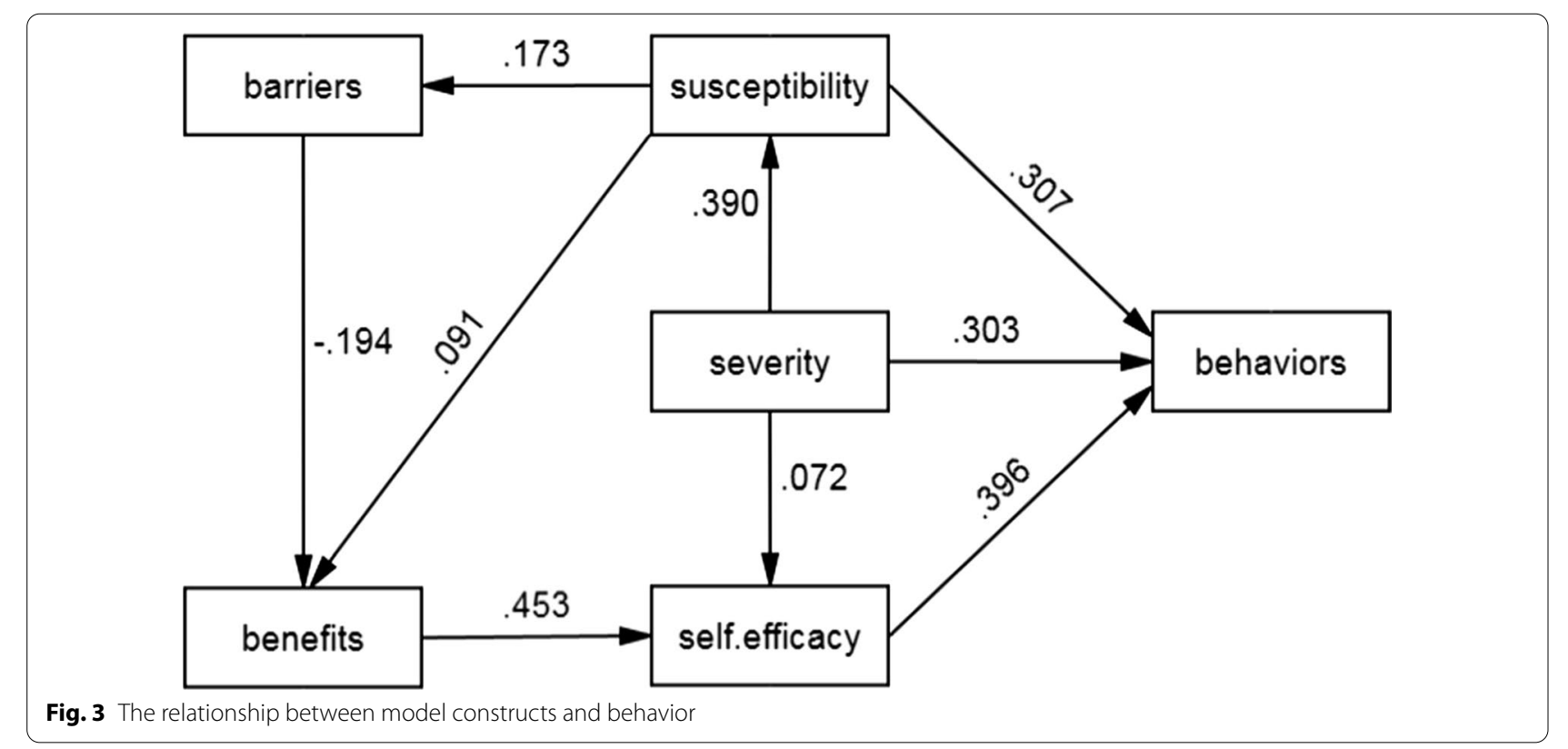

level of knowledge [31]. Contrary to the present findings, a number of other studies found no statistically significant correlation between knowledge and adoption of healthy behaviors $[22,32]$. Even in another study, insufficient knowledge showed to induce a better acceptance of the HPV vaccine [33]. Thus, knowledge can be seen 
Table 5 Direct and indirect effects of HBM constructs on GWs preventive behaviors in path analysis

\begin{tabular}{llcc}
\hline Variable name & Direct effects & Indirect effects & Total effects \\
\hline Severity & 0.303 & 0.152 & 0.455 \\
Self-efficacy & 0.396 & 0.000 & 0.396 \\
Susceptibility & 0.307 & -0.010 & 0.317 \\
Benefits & 0.000 & 0.179 & 0.179 \\
Barriers & 0.000 & -0.035 & -0.035 \\
\hline
\end{tabular}

as critically involved in forming attitude and behaviors. Adoption of new behaviors is easier when it is based on a correct knowledge, high awareness and positive attitude. Some research revealed that knowledge indirectly moderated the effect of attitude on the intention of HPV vaccination [34]. Undoubtedly, awareness-raising is the most influential factor in raising sex awareness, and awareness-raising through mass media can prevent the prevalence of sexually transmitted diseases among people. In Iran, contrary to other developing countries, sex education has been conspicuously absent, and this is mostly due to the dominant culture and traditions. Absence of any sex education for long can lead to a low overall level of sex knowledge in society and can be associated with higher risks of sexually transmitted diseases such as GW. Iranian women's knowledge of sex issues is truly limited. Thus, sex education is essential for Iranian women [10]. It is suggested that sex awareness be raised in both society and families so that everyone can benefit from this knowledge.
The present findings showed that the effect of perceived susceptibility on GW preventive behaviors was statistically significant. This finding points to the fact that women who perceive themselves at a higher risk of GW adopt more protective behaviors. In other words, if their perceived susceptibility is low, their susceptibility to and precision in adopting healthy protective behaviors may be low too. Resentstock (1982) in Ningrum (2016) maintained that those who perceive the adverse effects of a disease more than others show more tendency to medical preventive services [35]. Similarly, another study showed that women who perceived themselves more susceptible to uterine cancer tended more to receive HPV vaccine and the Pap tests to prevent cervical cancer [36, 37]. In another study, those with a higher perceived susceptibility showed a tendency to HPV vaccination 22.81 times as high as others [30]. In a review, Austin reported that low perceived susceptibility was a main barrier to administering the Pap test and breast self-administered test [38]. Contrary to the present findings, some other research showed that perceived susceptibility had no effect on the intention of receiving HPV vaccine in women [22, 39]. This divergence can be partly due to different demographic features of the participants, questionnaire content, sample size and statistical procedures. Researchers reckon that a certain level of perceived potential side effects of a disease is required before one is motivated to adopt a protective behavior [39]. Health specialists can report facts and figures about the infection at a national and international scale and, thus, increase women's perceived susceptibility to GW.

Table 6 Path coefficients and the variance in HBM constructs explained

\begin{tabular}{|c|c|c|c|c|c|c|c|}
\hline Path & & & $\beta$ & S.E & C.R & $p$ & $R^{2}$ \\
\hline Severity & $\rightarrow$ & Susceptibility & 0.390 & 0.040 & 11.370 & $<0.001$ & 0.152 \\
\hline Susceptibility & $\rightarrow$ & Barriers & 0.173 & 0.045 & 4.721 & $<0.001$ & 0.030 \\
\hline Susceptibility & $\rightarrow$ & Benefits & 0.091 & 0.031 & 2.444 & 0.015 & 0.040 \\
\hline Barriers & $\rightarrow$ & Benefits & -0.194 & 0.025 & -5.232 & $<0.001$ & \\
\hline Benefits & $\rightarrow$ & Self-efficacy & 0.453 & 0.034 & 13.662 & $<0.001$ & 0.211 \\
\hline Severity & $\rightarrow$ & Self-efficacy & 0.072 & 0.033 & 2.165 & 0.030 & \\
\hline Severity & $\rightarrow$ & Behaviors & 0.303 & 0.008 & 10.036 & $<0.001$ & 0.448 \\
\hline Susceptibility & $\rightarrow$ & Behaviors & 0.307 & 0.007 & 10.181 & $<0.001$ & \\
\hline Self-efficacy & $\rightarrow$ & Behaviors & 0.396 & 0.007 & 14.244 & $<0.001$ & \\
\hline
\end{tabular}

Table 7 Goodness of fit indices for the predictive model of GWs preventive behaviors

\begin{tabular}{|c|c|c|c|c|c|c|c|c|c|}
\hline $\mathrm{X}^{2}$ & DF & $\mathrm{X}^{2} / \mathrm{DF}$ & GFI & AGFI & $\mathrm{NFI}$ & CFI & IFI & RMSEA & RMR \\
\hline 8.985 & 6 & 1.497 & 0.996 & 0.986 & 0.988 & 0.996 & 0.990 & 0.026 & 0.260 \\
\hline
\end{tabular}


As the present findings showed, perceived severity was positively correlated with the adoption of GW preventive behaviors. In other words, those with a higher perceived severity of GW adverse effects tended more to adopt protective behaviors. Theoretically speaking, Rosen and Stock (1974) maintained that perceived severity can increase preventive medical measures [40]. According to Bakhtiari, when someone perceives conditions critical, s/ he tends to adopt a self-protective behavior [41]. In a similar vein, another study showed that women with a higher perceived fear of the mere thought of GW or cervical cancer and an increased heart rate agreed more than others with HPV vaccination [42]. Lee et al. maintained that perceiving cancer as a horrifying disease was the main reason for receiving HPV vaccines. As the participants with an intention of vaccination maintained, GW or uterine cancer can disrupt one's work, education and even love affairs [43]. Similarly, in a number of other studies, perceived severity showed to have a significant effect on the rate of using HPV vaccination to prevent cervical cancer [30, 44]. Contrary to the present findings, another study found no significant effect of perceived severity on women's intention of HPV vaccination [22]. This divergence can be partly explained by different demographic features, different questionnaire content, sample size and statistical methods.

The present researchers believe that knowledge, perceived susceptibility and severity together can encourage women to adopt healthy behaviors. As the present findings showed, knowledge, perceived susceptibility and severity were significantly correlated. Another study showed that knowledge managed to increase the rate of uterine cancer through affecting perceived severity [45]. It seems that if women have an adequate knowledge of GW preventive behaviors and symptoms and if they receive adequate and correct instructions with this regard, their perceived susceptibility to GW is increased. Thus, they tend more to perceive the severity of the disease and tend more to show preventive behaviors.

The present findings revealed that perceived benefits and barriers had no statistically significant correlation with GW preventive behaviors. Similarly, a number of studies showed no statistically significant correlation between perceived benefits and barriers and the intention of vaccination $[34,36,46]$. Contrary to the present findings, two other studies revealed the significant effect of perceived benefits and barriers on the intention of vaccination [30, 47]. These divergent findings can be partly explained by the different socio-demographic features of target research groups. In the majority of the above-mentioned studies, the aim was to screen for cervical cancer and receive HPV vaccines. However, in the present research, the aim of healthy behaviors was to prevent GW. It is noteworthy that though perceived benefits and barriers did not directly affect the target healthy behavior, path analysis showed the indirect effect of these constructs on the preventive behavior (moderated by perceived susceptibility and severity). These findings can be explained with several points in mind. Firstly, the questionnaire items probably did not reflect the participating women's perceived benefits and barriers. Secondly, it seems that the participants did not perceive the benefits of adopting GW preventive behaviors. Probably more time is needed to adopt the former healthy behavior and perceive its benefits. It is also speculated when women do not perceive the benefits of a certain behavior, it indirectly affects their perception of barriers. This could have affected the statistically insignificant correlation between perceived benefits and barriers and GW preventive behaviors.

In the present findings, self-efficacy showed to be the strongest predictor of adopting GW preventive behaviors. Another study also confirmed this finding and introduced self-efficacy as the strongest predictor of the intention of HPV vaccination [34]. In another study, self-efficacy was found to be significantly correlated with the intention of HPV vaccination [48]. The correlation between self-efficacy and healthy behaviors was explored too and self-efficacy showed to be strongly affecting healthy behaviors. Someone with a low level of self-efficacy is less likely to try to adopt a healthy behavior or to change an already established habit [49]. Contrary to the present findings, in some other studies, self-efficacy did not show to affect the intention of HPV vaccination [5052]. These differences can be partly due to participants' different demographic features and purposes of research. We can say that people with a high self-efficacy have a greater knowledge, as according to TPB, behavioral success directly depends on perceived behavioral control and intention of healthy behavior if and only if an individual is very well aware of the current conditions [53].

\section{Conclusions}

The present findings help to promote knowledge of the adoption of GWs preventive behaviors. In the light of the present findings we can conclude that HBM is a useful tool for health specialists as a theoretical framework for evaluating preventive programs and reducing sexually transmitted diseases such as GW preventive behaviors.

\section{Strengths and limitations}

One strength of the present research was the large sample size as it included Bandar Abbas population. Still the generalization of findings is limited. Another strength of the present research was using HBM as the theoretical framework for adopting GW preventive 
behaviors among women. To our knowledge, this model had not been previously used in exploring GW preventive behaviors among women. The present findings can be used to develop educational interventions, focus on effective basic constructs to compare prospective studies in the field. There were certain limitations too. For one, the data were collected as self-reports. Probably, women considered social acceptance in their responses though the researcher tried to emphasize the confidentiality of information to reduce this bias to some extent.

Another limitation of the present research is the selection bias because there were chances that those living in the same neighborhood showed similar behaviors. We attempted to lower the selection bias by using a multi-stage sampling and randomization to maximize demographic variety. Still, it is recommended that in future a wider range of demographic features be used to include various women participants.

Furthermore, this research was cross-sectional in type and, thus, making causal claims is deemed less appropriate. Finally, as the questionnaires were completed only by women who were willing to participate in the research, the results cannot be representative of the perceptions of those who refused to take part in the research.

\section{Abbreviations}

GW: Genital wart; HBM: Health belief model; SES: Socioeconomic status.

\section{Supplementary Information}

The online version contains supplementary material available at https://doi. org/10.1186/s12905-022-01649-6.

Additional file 1. The data collection instrument

Additional file 2. The data file.

\section{Acknowledgements}

The authors would like to thank Hormozgan University of medical science as their financial support. The authors would also like to express their gratitude to the participants for their sincere cooperation in this study.

\begin{abstract}
Authors' contributions
SSH, designed the study, supervised data collection, analyzed the data and reviewed the manuscript.; SD, designed the study, collected data, analyzed the data drafted the manuscript and critically reviewed the manuscript, AA; designed the study, reviewed the manuscript., SHM, analyzed the data and reviewed the manuscript, AA, PR, ZH AND VR reviewed the manuscript, All authors read and approved the final manuscript.
\end{abstract}

\section{Funding}

This research received a grant from Hormozgan University of medical science.

\section{Availability of data and materials}

All data generated or analysed during this study are included in this published article and its Additional file 1 and Additional file 2

\section{Declarations}

\section{Ethics approval and consent to participate}

This research was approved by Hormozgan University of medical sciences (\#IR.HUMS.REC.1398.267). All participants were required to sign an informed consent and were informed they could withdraw in any step of the research if they desired. For the participants below 18 years of age an informed consent was obtained from parents. We can confirm that all methods were performed in accordance with the relevant guidelines and regulations of research ethics.

\section{Consent for publication}

Not applicable.

\section{Competing interests}

The authors have no competing interests to declare.

\section{Author details}

${ }^{1}$ Mother and Child Welfare Research Center, Faculty of Nursing and Midwifery, Hormozgan University of Medical Sciences, Bandar Abbas, Iran. ${ }^{2}$ Department of Obstetrics and Gynecology, Maternal-Fetal Medicine Research Center, School of Medicine, Shiraz University of Medical Sciences, Shiraz, Iran. ${ }^{3}$ Infectious and Tropical Diseases Research Center, Hormozgan Health Institute, Hormozgan University of Medical Sciences, Bandar Abbas, Iran. ${ }^{4}$ Student Research Committee, Hormozgan University of Medical Sciences, Bandar Abbas, Iran.

${ }^{5}$ Tobacco and Health Research Center, Hormozgan University of Medical Sciences, Bandar Abbas, Iran. ${ }^{6}$ Social Determinants in Health Promotion Research Center, Hormozgan Health Institute, Hormozgan University of Medical Sciences, Bandar Abbas, Iran.

Received: 13 July 2021 Accepted: 3 March 2022

Published online: 08 March 2022

\section{References}

1. Dareng EO, Adebamowo SN, Famooto A, Olawande O, Odutola MK, Olaniyan Y, Offiong RA, Pharoah PP, Adebamowo CA. Prevalence and incidence of genital warts and cervical human Papillomavirus infections in Nigerian women. BMC Infect Dis. 2019;19(1):27.

2. Buenconsejo L, Kothari-Talwar S, Yee K, Kulkarni A, Lara N, Roset M, Giuliano AR, Garland S. Estimating the burden of illness related to genital warts in the Philippines: a nationally representative cross-sectional study. Infect Agents Cancer. 2019;14(1):26.

3. Khodakarami N, Clifford GM, Yavari P, Farzaneh F, Salehpour S, Broutet N, Bathija H, Heideman DA, van Kemenade FJ, Meijer CJ. Human papillomavirus infection in women with and without cervical cancer in Tehran, Iran. Int J Cancer. 2012;131 (2):E156-61.

4. Malakouti J, Mirghafourvand M, Gorbani M, Salehi Poormehr H, Pourasad Shahrak S, Jafari Shabiri M. Incidence of Human Papilloma Virus (HPV) infection and its relevant factors among women referring to Alzahra Therapeutic-Educational Center of Tabriz, September 2013 to March 2014. Iran J Obstet Gynecol Infertil. 2016;18(185):16-22.

5. Jamdar F, Farzaneh F, Navidpour F, Younesi S, Balvayeh P, Hosseini M, Ghodssi-Ghasemabadi R. Prevalence of human papillomavirus infection among Iranian women using COBAS HPV DNA testing. Infect Agents Cancer. 2018;13(1):1-5.

6. Shafaghi B, Jarollahi A, Yousefzadeh B, Ameri A, Moghadam S, Mostafavi M. Human papilloma virus prevalence and types among Iranian women attending regular gynecological visits. Rep Radiother Oncol. 2013;1(2):73-9.

7. Hosseini Z, Seyrafi N, Aghamolaei T, Mohseni S, Alavi A, Dadipoor S. The effectiveness of a model-based health education program on genital warts preventive behaviors: a quasi-experimental study. Infect Agents Cancer. 2021;16(1):1-11.

8. Kjær SK, Trung Nam T, Sparen P, Tryggvadottir L, Munk C, Dasbach E, Liaw K-L, Nygård J, Nygård M. The burden of genital warts: a study of nearly 70,000 women from the general female population in the 4 Nordic countries. J Infect Dis. 2007;196(10):1447-54. 
9. Camenga DR, Dunne EF, Desai MM, Gee J, Markowitz LE, Desiliva A, Klein NP. Incidence of genital warts in adolescents and young adults in an integrated health care delivery system in the United States before human papillomavirus vaccine recommendations. Sex Transm Dis. 2013;40(7):534-8.

10. Qaderi K, Mirmolaei ST, Geranmayeh M, Hasani SS, Farnam F. Iranian women's psychological responses to positive HPV test result: a qualitative study. BMC Womens Health. 2021;21(1):1-11.

11. Pakpour Hajiagha A, Mohammadi Zeidi I, Mohammadi Zeidi B. The Impact of health education based on theory of planned behavior on the prevention of aids among adolescents. Iran J Nurs. 2012;25(78):1-13.

12. Roozbeh N, Safari Moradabadi A, Dadipoor S. Evaluation of awareness and high-risk behavior associated with genital wart in married female students. Ann Trop Med Public Health. 2017;10(6):1704-8.

13. Nekooi M, Ayazi S, Gandomi M, Moosavi SG, Fakhri A. Level of knowledge about human papillomavirus infection among women of Kashan City, Iran. Int Arch Health Sci. 2016;3:7-12.

14. Soori T, Hallaji Z, Noroozi-Nejad E. Genital warts in 250 Iranian patients and their high-risk sexual behaviors. Arch Iran Med. 2013;16(9):518.

15. Leung W, Chan P, Lau K, Ho K. The prevalence of human papilloma virus in the anal region of male Chinese attendees in three public sexually transmitted disease clinics in Hong Kong. Hong Kong J Dermatol Venereol. 2011;19(1):6-13.

16. Najafi F, Hematti M, Jalilian N. Epidemiologic study of genital warts among women in Kermanshah Province, Iran. Acta Med Mediterr. 2016;32:1955-8.

17. Mahdavi S, Lotfi MH, Kamalinejad M, Emtiazy M, Karimi-Zarchi M, Enayatrad M, Naghshi M, Faghih FS. The epidemiologic investigation of genital warts within the females referred to Shahid Sadoughi Hospital in Yazd-a case series study. J Community Health Res. 2015;4(3):168-76.

18. Khani Jeihooni A, Ghaedi R, Kashfi SM, Khiyali Z. Effect of education based on the health belief model in the prevention of sexually transmitted diseases in couples participating in premarriage training classes. J Educ Community Health. 2018;4(4):4-12.

19. Feyisa GC, Temesgen H. Perceived benefits and barriers toward cervical cancer screening among women $\geq 15$ years in Arsi Zone, Southeastern Ethiopia: application of the health belief model in a community-based cross-sectional study. J Cancer Res Pract. 2019;6(1):7.

20. Jeihooni AK, Jormand H, Ansari M, Harsini PA, Rakhshani T. The effect of educational intervention based on health belief model and social support on testicular self-examination in sample of Iranian men. BMC Cancer. 2021;21(1):1-10.

21. Suligoi B, Vittori G, Salfa MC, Timelli L, Corsini D, Fattorini G, Mariani L. Prevalence and incidence of external genital warts in a sample of Italian general female population. BMC Infect Dis. 2017;17(1):1-8.

22. Christy SM, Winger JG, Raffanello EW, Halpern LF, Danoff-Burg S, Mosher CE. The role of anticipated regret and health beliefs in HPV vaccination intentions among young adults. J Behav Med. 2016;39(3):429-40.

23. Gerend MA, Shepherd JE. Predicting human papillomavirus vaccine uptake in young adult women: comparing the health belief model and theory of planned behavior. Ann Behav Med. 2012:44(2):171-80.

24. Petersen L, Nielsen J, Vaesel H, Brønsgaard P, Kolby P, Madsen K. Knowledge of human papilloma virus-associated disease among women in general practice. Ugeskr Laeger. 2009;171(14):1173-7.

25. Banura C, Mirembe FM, Orem J, Mbonye AK, Kasasa S, Mbidde EK. Prevalence, incidence and risk factors for anogenital warts in Sub Saharan Africa: a systematic review and meta analysis. Infect Agents Cancer. 2013;8(1):27.

26. Daou KN, Bou-Orm IR, Adib SM. Factors associated with waterpipe tobacco smoking among Lebanese women. Women Health. 2018;58:1-11.

27. Namdar A, Bigizadeh S, Naghizadeh MM. Measuring health belief model components in adopting preventive behaviors of cervical cancer. J Fasa Univ Med Sci. 2012;2(1):34-44.

28. Melki I, Beydoun H, Khogali M, Tamim H, Yunis K. Household crowding index: a correlate of socioeconomic status and inter-pregnancy spacing in an urban setting. J Epidemiol Community Health. 2004;58(6):476-80.
29. Farshbaf-Khalili A, Shahnazi M, Salehi-Pourmehr H, Faridvand F, Asgarloo Z. Behavioral prevention regarding sexually transmitted infections and its predictors in women. Iran Red Crescent Med J. 2014;16(8):e18346.

30. Fitriani Y, Mudigdo A, Andriani RB. Health belief model on the determinants of human papilloma virus vaccination in women of reproductive age in Surakarta, Central Java. J Health Promot Behav. 2018;3(1):16-26.

31. Sari AP, Syahrul F. Faktor yang berhubungan dengan tindakan vaksinasi hpv pada wanita usia dewasa. J Berk Epidemiol. 2014;2(3):321-30.

32. Calderón-Mora J, Ferdous T, Shokar N. HPV vaccine beliefs and correlates of uptake among hispanic women and their children on the US-Mexico border. Cancer Control. 2020;27(1):1073274820968881.

33. Pew Research Center W, D.C.5 facts about vaccines in, the U.S. 2019. Accessed July 14 hwp, org/ fact-tank/2019/03/19/5-facts-about-vaccines-in-the-u-s/.

34. Chunuan S, Wiwattanawongsa K, Widayati A. A predictive model of human papillomavirus vaccination intention among young women in southern Thailand. Pac Rim Int J Nurs Res. 2021;25(2):298-311.

35. Ningrum DNS. Path Analysis Hubungan Pendidikan dan Konstruk Health Belief Model dengan Kinerja Kader Pada Pengendalian Kasus Tuberkulosis Di Puskesmas Baki Kabupaten Sukoharjo. UNS (Sebelas Maret University); 2016.

36. Nugrahani RR, Budihastuti UR, Pamungakasari EP. Health belief model on the factors associated with the use of HPV vaccine for the prevention of cervical cancer among women in Kediri, East Java. J Epidemiol Public Health. 2017;2(1):70-81.

37. Khani Jeihooni $A$, Jormand $H$, Harsini PA. The effect of educational program based on beliefs, subjective norms and perceived behavior control on doing pap-smear test in sample of Iranian women. BMC Womens Health. 2021;21(1):1-10.

38. Austin LT, Ahmad F, McNally M-J, Stewart DE. Breast and cervical cancer screening in Hispanic women: a literature review using the health belief model. Womens Health Issues. 2002;12(3):122-8.

39. Karimy M, Azarpira H, Araban M. Using health belief model constructs to examine differences in adherence to pap test recommendations among Iranian women. Asian Pac J Cancer Prev APJCP. 2017;18(5):1389.

40. Rosenstock IM. Historical origins of the health belief model. Health Educ Monogr. 1974;2(4):328-35.

41. Bakhtari Aqdam F, Nuri Zadeh R, Sahebi L. Effect of education based on Health Belief Model on Believe promotion and screening behaviours of breast cancer among women reffered to Tabriz health centers. Medl J Tabriz Uni Medl Sci. 2012;2012(33):25-31.

42. He C. Use of the health belief model to understand HPV vaccine behavior in female undergraduates. Ypsilanti: Eastern Michigan University; 2016.

43. Lee A, Ho M, Cheung CKM, Keung VMW. Factors influencing adolescent girls' decision in initiation for human papillomavirus vaccination: a cross-sectional study in Hong Kong. BMC Public Health. 2014;14(1):1-10

44. Wigati PW: Analisis jalur dengan health belief model tentang penggunaan skrining inspeksi visual asam asetat untuk deteksi dini kanker serviks pada wanita usia subur di kota Kediri. UNS (Sebelas Maret University); 2016.

45. Annan FM, Asante KO, Kugbey N. Perceived seriousness mediates the influence of cervical cancer knowledge on screening practices among female university students in Ghana. BMC Womens Health. 2019;19(1):1-8

46. Aldohaian Al, Alshammari SA, Arafah DM. Using the health belief model to assess beliefs and behaviors regarding cervical cancer screening among Saudi women: a cross-sectional observational study. BMC Womens Health. 2019;19(1):1-12.

47. Park S, Jang I, Lee JL, Kim Y. Factors affecting vaccination status of female adolescents subject to the Korean national HPV immunization program: focusing on mothers' HPV knowledge and heath beliefs of HPV vaccines. J Korean Soc Sch Health. 2020;33(1):58-66.

48. He C. Use of the health belief model to understand HPV vaccine behavior in female undergraduates. Ypsilanti: Eastern Michigan University; 2015.

49. Karimy M, Gallali M, Niknami S, Aminshokravi F, Tavafian S. The effect of health education program based on Health Belief Model on the 
performance of Pap smear test among women referring to health care centers in Zarandieh. J Jahrom Univ Med Sci. 2012;10(1):53-9.

50. Krawczyk AL, Perez S, Lau E, Holcroft CA, Amsel R, Knäuper B, Rosberger Z. Human papillomavirus vaccination intentions and uptake in college women. Health Psychol. 2012;31(5):685.

51. Bennett KK, Buchanan JA, Adams AD. Social-cognitive predictors of intention to vaccinate against the human papillomavirus in collegeage women. J Soc Psychol. 2012;152(4):480-92.

52. Ratanasiripong NT, Cheng A-L, Enriquez M. What college women know, think, and do about human papillomavirus (HPV) and HPV vaccine. Vaccine. 2013;31(10):1370-6.

53. Ajzen I. The theory of planned behavior. Organ Behav Hum Decis Process. 1991;50(2):179-121.

\section{Publisher's Note}

Springer Nature remains neutral with regard to jurisdictional claims in published maps and institutional affiliations.

- fast, convenient online submission

- thorough peer review by experienced researchers in your field

- rapid publication on acceptance

- support for research data, including large and complex data types

- gold Open Access which fosters wider collaboration and increased citations

- maximum visibility for your research: over $100 \mathrm{M}$ website views per year

At BMC, research is always in progress.

Learn more biomedcentral.com/submissions 